\title{
Model-based assessment of the pattern differences and the equity of national carbon emissions in China during 2000-2010
}

\author{
Qiuxian Wang ${ }^{\text {a, b, c }}$, Zhiqiang Gao ${ }^{\text {a, * }}$, Jicai Ning ${ }^{\text {a }}$ \\ a Yantai Institute of Coastal Zone Research, Chinese Academy of Sciences, Yantai, China \\ ${ }^{\mathrm{b}}$ University of Chinese Academy of Sciences Beijing, China \\ ${ }^{\mathrm{c}}$ Institute of Geography and Planning, Ludong University, Yantai, China
}

\section{A R T I C L E I N F O}

\section{Article history:}

Received 27 March 2014

Received in revised form

13 August 2014

Accepted 21 August 2014

Available online 30 August 2014

\section{Keywords:}

Carbon emissions

The differences of spatial pattern

3E model

Remote sensing survey

Carbon sink

\begin{abstract}
A B S T R A C T
Land cover information of China was extracted using the supervised classification of remote sensing data and the carbon sink and carbon emissions of each province were calculated by combining the statistical data with the method of the Intergovernmental Panel on Climate Change (IPCC) 2006 listing. With the newly built 3E model, the three indexes of ESI (ecological support index), EDI (equitable distribution index) and EEI (economic efficiency index) were calculated and their spatial pattern characteristics and regional differences over time were analyzed. The research results indicated that as the forest coverage rate increased, the carbon sink of the ecosystem in China also increased. ESI in the central and western China was tending to decrease, while ESI in the eastern coast was growing. Although the EEI gap between eastern China and western China was large, their EDI value gap was becoming shrinking as the economic growth shifted towards the central China and western China. The $3 \mathrm{E}$ values which were calculated with the consideration of ecology, equity and efficiency for China's carbon emissions indicated that the carbon emissions in half provinces of China were in good conditions, with benign ecosystem circulation, fairness and high economic efficiency in the recent 11 years. These results could act as references for China's low carbon economic development and also could provide guidance for the spatial pattern planning of China's carbon emissions.
\end{abstract}

๑) 2014 Elsevier Ltd. All rights reserved.

\section{Introduction}

Currently, global warming has a significant influence on the earth's environment and human life, and it has been a popular topic of global change researches. The increase in carbon dioxide emissions is considered to be one of the most important causes of global warming, in which human activities play an important role in the terrestrial carbon library (Qin et al., 2007, IPCC, 2007, 2008). As a result, researchers in all countries of the world have attached great importance to the study of carbon emissions since the 1980s and have proposed different simulation methods from different perspectives to understand more accurately the effects of carbon emissions and to control carbon emissions to slow global warming trends (Cox et al., 2002; Leemans et al., 2002; Powlson et al., 2011). As a developing country, China has experienced rapid economic growth since the economic reform and encouraging foreign investment, which has inevitably led to an increase in carbon dioxide emissions

\footnotetext{
* Corresponding author.

E-mail address: zqgao@yic.ac.cn (Z. Gao).
}

(Energy research institute, 2003). In 2007, China became the world's largest country in terms of energy consumption and carbon emissions (International Energy Agency, 2010). As a responsible power, China formulated and implemented a series of policies and measures to promote energy savings and emissions reduction. During the period of the "11th five-year plan", China's primary energy consumption growth rate was approximately $6.7 \%$, which corresponds to a $3.4 \%$ drop compared to the period of the "10th five-year plan" (Liao and Wei, 2011). China's efforts regarding energy conservation and the reduction of carbon emissions have resulted in a $20 \%$ drop in energy intensity. In 2009, China proposed the goal of reducing the intensity of carbon emissions by $45 \%$ by 2020 compared to that in 2005 , the realization of which requires the joint effort of all the provinces, autonomous regions and municipalities directly under the central government in China. Then the problem comes. Shall all the provinces pay equal efforts for the goal since each province has different carbon emissions according to its own natural and social conditions? What's the regional difference for carbon emissions? It is difficult to solve this problem because there is no unified model in the world now, and there are still different sounds among different countries. The developed countries tend to ignore the history of 
carbon emissions, focusing on the research of how to allocate the world's future carbon emissions credits (J. A. Duro, 2013), while the developing countries try their best to emphasize the fairness. In China, scholars were more likely to adopt the cumulative emissions of a certain historical period Ding et al., 2009, Li and Qi, 2011] or the gini coefficient (Huang and Yang, 2011) for studying the regional carbon emissions based on fairness. As to the study of the pattern of differences, most scholars consider it in absolute quantity with different calculation methods. In large scale research, the IPCC listing method (IPCC, 2006) is often used to calculate carbon emissions for its acknowledgment in worldwide. In China, Some scholars like Shu (2012), Lu et al. (2012), Xiong et al. (2012), Zou et al. (2013) analyzed China's energy carbon emissions by using it. In recent years, the factor decomposition method is also used in China to performed quantitative analyses for regional carbon emissions which maybe more complicated and may have more uncertainty. For example researchers of Li and Sun (2011), Li and Li (2010), Zha and Zhou (2007), Xu et al. (2006), used the IPAT model (Impact = Population * Affluence * Technology), the STIRPAT model (Stochastic Impacts by Regression on PAT), Kaya factorization, and LMDI (Logarithmic Mean Divisia Index) method respectively in the study of China's carbon emissions, and their results varied. As to the smaller region, the scholars at home and abroad often use carbon flux which has been tested by Static box - gas chromatography or by Eddy covariance technique (Wang et al., 2008) which may be very accurate in a little place but it is very hard for applying them in a large scale. Overall consideration, our study used the IPCC listing method. However, the absolute amount of carbon emissions does not correspond to the size of the regional carbon libraries, which means that some high carbon emissions in certain provinces may be offset by their higher carbon sink capacities. Thus, it is unfair for some provinces only considering their absolute carbon emissions or historical cumulate amount regardless their different ecological conditions and social economic development levels. It is particularly important to perform research on carbon emissions under fair conditions to enable proper comparisons.

Based on the above consideration and inspired by Chen et al. (2012), the authors tried to set up a 3E model which includes ecology, equity and efficiency under the frame of ecological economics and can reflect the pattern differences of China's provincial carbon dioxide emissions on fairness comprehensively. With $\mathrm{Y}_{3 \mathrm{E}}$ values for the years of 2000, 2005 and 2010 in China, we can see the reasonable trends of carbon emissions of each province clearly besides the absolute quantity changing trends. Thus we think that $\mathrm{Y}_{3 \mathrm{E}}$ will not only provide a new way for the study of regional spatial differences in carbon emissions but also give fundamental references for the future distribution of carbon dioxide emissions among different provinces of China on fairness.

\section{Methods}

\subsection{Data sources}

The paper considered the three periods of NDVI (Normalized Difference Vegetation Index) data of 2000, 2005 and 2010 from SPOT NDVI data with 36 VGT-S10 files each year. The Annual Stacking images were synthesized from the annual NDVI data set of the time series with 36 bands. This study used the DEM (Digital Elevation Model) data from SRTM3 (Shuttle Radar Mission) to assist in the Topography processing after land cover classification, whose spatial resolution is $90 \mathrm{~m} \times 90 \mathrm{~m}$. At the same time, the study used the land use data from the Chinese resources and environment remote sensing data base of 2000 and 2005 as the accuracy references, which were extracted through the TM(Thematic Mapper)/
ETM( Enhanced Thematic Mapper)/ETM + data by computer based artificial interpretation.

The data on fossil fuels used in this paper are from the fossil fuels Chinese energy statistical yearbook (NBS, 2001-2012a), and the cement production comes from the Chinese cement yearbook (NBS, 2001-2012b); the Chinese population, the Gross Domestic Product (GDP) and other social and economic data are from China statistical yearbook (NBS, 2001-2012c), and the carbon emissions parameters of energy and cement are from the IPCC 2006 listing.

\subsection{Extraction methods for the classification information of land cover}

There are six land cover types in the Chinese land use maps of 2000 and 2005, which include Cropland, Woodland, Grassland, Water body, Built-up area and Unused land. All six land cover types have obvious characteristics on the NDVI time series, according to which we can classify the land cover (Peng et al., 2009). In the NDVI classification, the method of spectral angle mapping (SAM) in supervised classification was used (De Carvalho et al., 2006) according to equation (1) (Tang et al., 2005).

$\cos (t a)=\frac{\mathrm{F}_{\mathrm{p}} * \mathrm{~F}_{\text {roi }}}{\left|\mathrm{F}_{\mathrm{p}}\right|\left|\mathrm{F}_{\text {roi }}\right|}=\frac{\sum_{i=1}^{n} \mathrm{~F}_{\mathrm{p}} i \mathrm{~F}_{\text {roi }} i}{\sqrt{\sum_{i=1}^{n} \mathrm{~F}_{\mathrm{p}} i \mathrm{~F}_{\mathrm{p}} i} \sqrt{\sum_{i=1}^{n} \mathrm{~F}_{\text {roi }} i \mathrm{~F}_{\text {roi }} i}}$

Among the classification items, ta denotes the angle between the pixel curve and the curve of the ROI (Regions of Interest), and Fp and $\mathrm{F}_{\mathrm{roi}}$ denote the time sequence vectors of the pixel and the ROI, respectively, with $i=1 \ldots n, n=36$.

Then with the expert model once used by William and Maik (2005) the post classification process was performed and we got the land use classification graphs which were shown in Figs. 1 and 2 , respectively. Based on the validation of the classification accuracy, we calculated the total carbon sinks of different provinces with the land classification data from the three periods in combination with the carbon exchange rates of different vegetation (e.g., woodland and grassland).

\subsection{Calculation methods for determining China's $\mathrm{CO}_{2}$ emissions}

According to the fourth assessment report of the IPCC in 2007, the main source of increased greenhouse gases is the burning of fossil fuels (IPCC, 2007a). And carbon dioxide emissions resulting from the burning of fossil fuels was nearly $95.13 \%$ of the world total emissions in 2004. Worldwide, the emission inventory method of the IPCC2006 is often used according to 2006 IPCC Guidelines for National Greenhouse Gas Inventories (IPCC, 2007b), so we likewise used it to calculate the carbon emissions of fossil fuels and cement consumption in China.

1) Calculation method for determining $\mathrm{CO}_{2}$ emissions for fossil fuels

To avoid larger errors made by the direct use of the primary energy data, the data used for this article are from the energy statistical yearbook of China pertaining to eight classes of final energy data: raw coal, coke, crude oil, gasoline, kerosene, diesel oil, fuel oil and natural gas. And with formula 2 we could calculate each kind of carbon emissions.

$Y_{e}=\sum_{i j} F_{i j y} * E F_{i}$

In formula 2, $Y_{e}$ denotes the $\mathrm{CO}_{2}$ emissions for the various fuels and its unit is tons of $\mathrm{CO}_{2} . F_{i j y}$ is the activity intensity, which denotes 


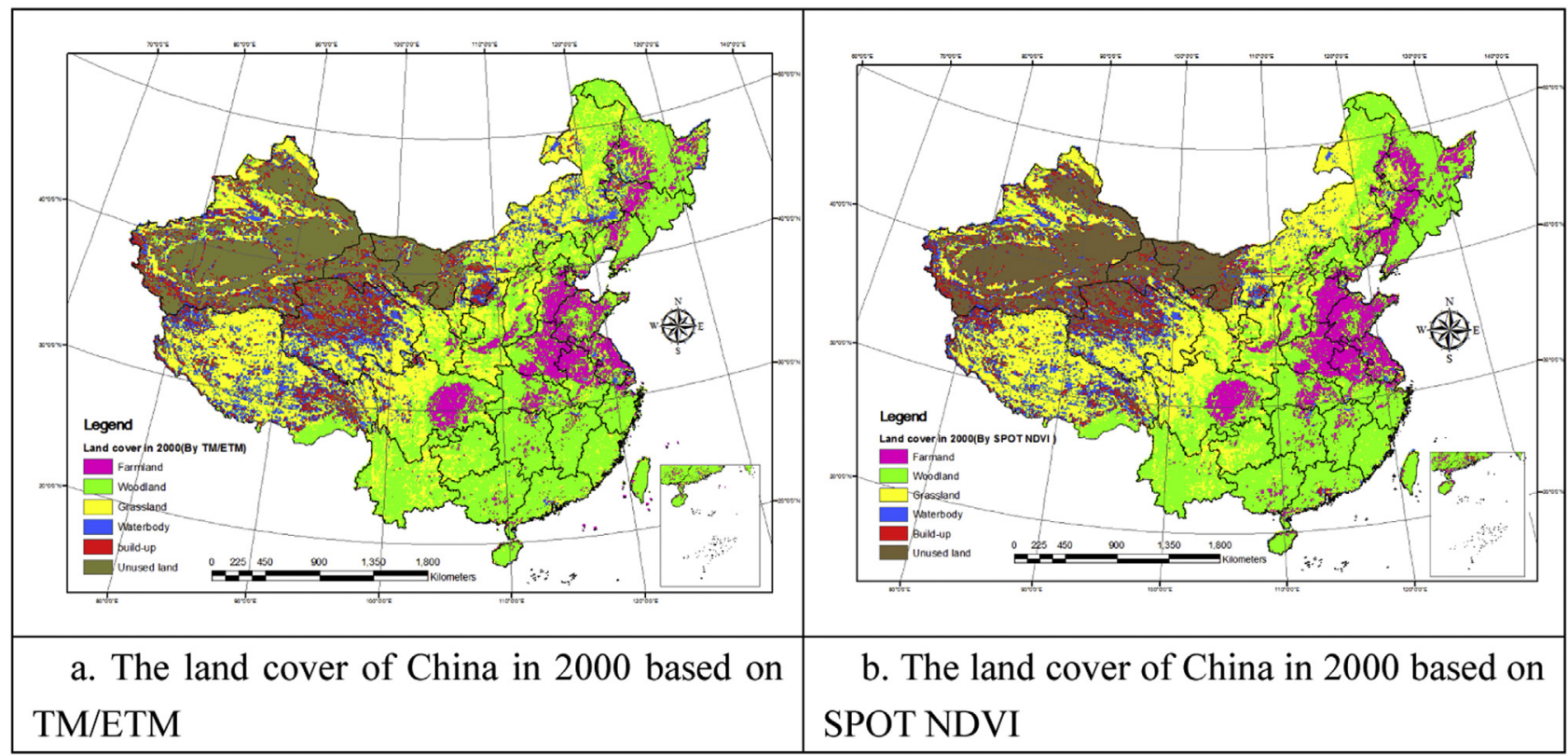

Fig. 1. Comparison of the land cover data from TM/ETM and SPOT NDVI.

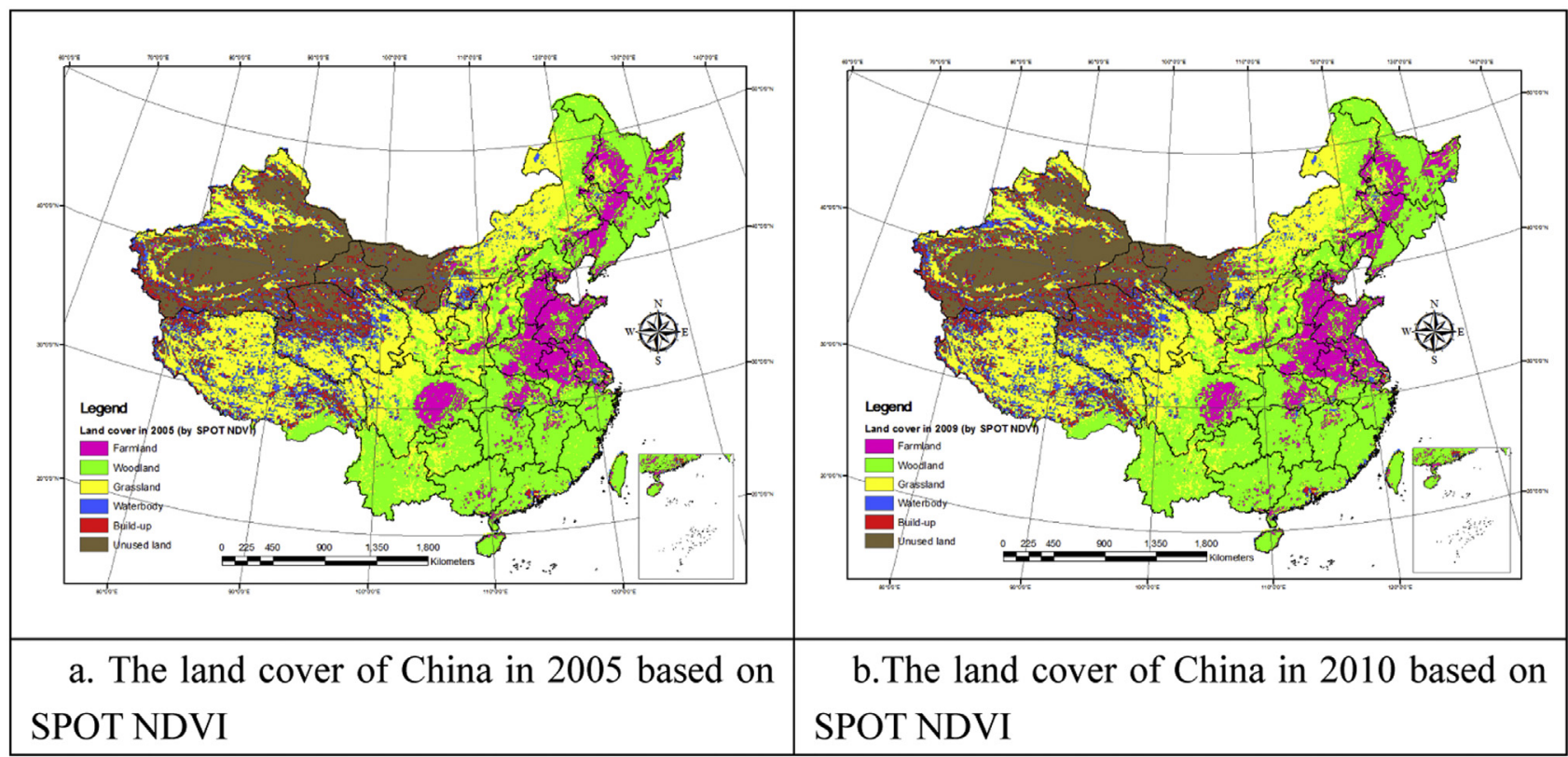

Fig. 2. Land cover in China in 2005 and 2010 determined by SPOT NDVI.

the consumption of the fuel $i$ (a quantity that is often calculated by mass or volume) in the year $y$ of the province $j . E_{i j}$ is the suggested $\mathrm{CO}_{2}$ emission factor for fuel $i$ and its unit is tons of $\mathrm{CO}_{2} /$ ton of fuel $i$. And

$E F_{i}=O X I D_{i} * E F_{\mathrm{CO}_{2}, i} * N C V_{i}$

in which $N C V_{i}$ denotes the net calorific value unit mass or volume of the fuel $i$ (energy content) and is a nationally designated value. $O X I D_{i}$ is the oxidation rate for fuel $i$, and is the IPCC default value. $E F_{\mathrm{CO} 2, i}$ is the default $\mathrm{CO}_{2}$ emission factor for fuel $i$ per unit energy and is the IPCC default value that is equal to the default carbon content of fuel $i \times 44 / 12$.
2) Calculation method for determining $\mathrm{CO}_{2}$ emissions for the cement production process

According to the guidance of the chapter 6 in 2006 IPCC guidelines for national greenhouse gas inventories (IPCC, 2006), the clinker production can be calculated with the cement output data. Due to the uncertainty of China's provincial cement types and the import and export data of clinker cement, and considering that China's cement exports is not large, accounting for $3 \%$ of the total cement production (Lu et al., 2012), this paper uses a clinker content of $75 \%$ to calculate the carbon dioxide emissions of the cement production process (Lu et al., 2012). The formula is as follows: 
$Y_{c e}=M_{c} * E F_{c l c}=M_{c} * 0.75 * 0.52=M_{c} * 0.39$

in which $\mathrm{Y}_{\mathrm{ce}}$ is the $\mathrm{CO}_{2}$ emissions for the cement production process with its unit is tons of $\mathrm{CO}_{2}$. is the $\mathrm{CO}_{2}$ emission factor for the cement clinker, and the default clinker emission factor corrected by the correction of CKD ( Cement Kiln Dust)given in the IPCC2006 is 0.52 tons of $\mathrm{CO}_{2}$ /ton of clinker(IPCC, 2006). $\mathrm{M}_{\mathrm{C}}$ denotes the activity data, that is, the cement productions for one year in each province, which are all from the China cement yearbook with their unit tons. An emission factor of 0.39 indicates that each ton of cement emits 0.39 tons of $\mathrm{CO}_{2}$.

\subsection{Model construction for the $3 E$ index}

As is considered in the Introduction, the authors emphasize that it is unfair to research the pattern differences of provincial carbon emissions only with their absolute quantity. Different regions have different geographical area, different population, different land use types, different economic development levels and different environmental bearing capacities. Supposing that the carbon emission in Province A is higher than that of in Province B, it is hard to say that we should attribute fewer or higher credits to Province $A$ in the future. If there are much more forests in Province A, and its vegetation carbon sequestration ability is very strong, which can reduce carbon dioxide from the atmosphere, we say that its carbon emission is within its ecological carrying capacity, so it is reasonable to attribute more carbon emission credit to Province A. So inspired by Chen Hua (2012), the authors try to construct a model which can include regional ecology, equity and efficiency besides the absolute quantity, then transform them into a measurable indicator $Y_{3 E}$ using the Delphi method.

That is.

$Y_{3 E}=\sum_{i=1}^{i=3} r_{i} \times I_{i}$

in which, Ii denotes the three indexes of the ecological support index (ESI), the equitable distribution index (EDI) and economic efficiency index (EEI). And $r_{i}$ is the weight of each index obtained by Delphi method. Firstly we designed the questionnaire and proposed the purpose of the model building by indicating that regional carbon emissions not only had close relations to the region's economy development but also were effected deeply by regional carbon absorption ability of vegetables. Then we sent them out to ten experts in the research of carbon emissions coming from Academy of Sciences, institutions of higher learning and the development and reform commission. Because the statistical results of experts' opinions are consistent for the first round, we took the arithmetic average to each weight, which meant the weight of ESI, EDI and EEI were 0.4, 0.2, 0.4 respectively. The calculation method of each index is designed as the following:

\section{1) Ecological support index (ESI)}

From viewpoint of ecology, the carbon sink in each province should be greater than its carbon emission, so that the content of $\mathrm{CO}_{2}$ can be maintained at a certain level and the province's ecological environment is in good condition (Lu et al., 2012). If the ratio of carbon emissions in one province is greater than that of its carbon sinks, we say that the province infringes on the interests of other regions and causes other regions to bear much burden for the impacts that its carbon emissions have on the ecological environment. On the contrary, if the ratio of carbon emissions in one province is less than that of its carbon sinks, it has a relatively high level of ecological capacity and significantly contributes to the reduction of carbon emissions pressure on the ecological environment (IPCC, 2007c). From this view, the authors calculate the ESI using the following formula:

Ecological support index $(\mathrm{ESI})=$ the ratio of its carbon sink/its carbon emission.

$E S I=\frac{A_{i}}{A} / \frac{Y_{i}}{Y}$

in which $A_{i}$ and $A$ are the regional carbon sink and national carbon sink values respectively, and $Y_{i}$ and $Y$ are the regional carbon emissions and the national carbon emissions respectively. All the units of $A$ and $Y$ is tons of $\mathrm{CO}_{2}$.

Regarding the carbon sink, the authors selected forest land and grass land as the primary carbon sink resources to calculate the carbon sink (NBS, 2010; Zeng and Pang, 2010; Zhang et al., 2010; Cai et al., 2005; He, 2006). The formula for estimating the carbon sink value is as follows:

$A=\sum_{i=1}^{i=n} T_{i} \times S_{i}$

in which $A$ is the total carbon sink value of the different land use types with their unit tons of $\mathrm{CO}_{2}$ and $T_{i}$ is the area of different land use types with its unit is $\mathrm{km}^{2}$, which includes forestry land area and grassland area. $S i$ is the carbon sink coefficient for land use type $i$, following Fang et al. (2007) (the carbon sink coefficient of the forest is $5.77 \mathrm{~kg} / \mathrm{m}^{2} \mathrm{y}$, and the carbon sink coefficient of the grassland is $0.0021 \mathrm{~kg} / \mathrm{m}^{2} \mathrm{y}$ ). Additionally, the area data of the forestry land and grassland are extracted from the remote sensing land use data of 2000, 2005 and 2010.

If the calculated ESI is greater than 1, the province has a relatively high carbon ecological capacity and contributes to other regions. An ESI lower than 1 indicates that the region's carbon sinking ability contributes less than its carbon emissions, meaning that the region has relatively low carbon ecological capacity and its greenhouse effect is characterized by external carbon emissions and needs other regions to mitigate the effect.

\section{2) Equitable distribution index (EDI)}

In the $1990 \mathrm{~s}$, as representatives of the developing countries, Chinese scholars began to focus on the fairness of the international climate regime. As an early appeared fair distribution index, per capita carbon emission has a realistic significance, and now has been recognized in the world (Chen, 2012). At the same time, the authors think that different area in the face of the same amount of carbon emissions, their increased concentration of carbon dioxide in the atmosphere is different. So the construction of the equitable distribution index (EDI) in this article is based mainly on the calculation of the $\mathrm{CO}_{2}$ emission density and the $\mathrm{CO}_{2}$ emissions per person in one year. In consideration of the international recognition for the carbon emissions per person and China's eastern Hu Huanyong line where is suitable for human survival with large population density, the weights of the carbon emission density and carbon emissions per person were designed to be 0.3 and 0.7 respectively(Wang et al., 2014). If the province with its per capita carbon emissions is higher than the national average level, we say that their regional per capita emission takes other provinces' carbons emissions space in the principle of fairness. The same is true for the regional density of carbon emissions. To put the two fair distribution indexes into the $3 \mathrm{E}$ model, and let them correspond 
with the other two indexes which are positively related with $\mathrm{Y}_{3 \mathrm{E}}$, we took their reciprocal as EDI. The specific formula is as follows:

$$
E D I=\frac{1}{0.7 * \overline{Y_{p i}} / \overline{Y_{p}}+0.3 * \overline{Y_{s i}} / \overline{Y_{s}}}
$$

in which $Y_{p}$ is the $\mathrm{CO}_{2}$ emissions per person in one year and equals the direct ratio of provincial $\mathrm{CO}_{2}$ emissions and its statistical population with its unit tons of $\mathrm{CO}_{2}$ per person; $\overline{Y_{p}}$ and $\overline{Y_{p i}}$ denote the national and provincial carbon emissions per capita, respectively; $Y_{S}$ denotes the carbon emission density and is equal to the direct ratio of carbon dioxide emissions and the corresponding area with its unit tons of $\mathrm{CO}_{2}$ per $\mathrm{km}^{2}$; and $\overline{Y_{s}}$ and $\overline{Y_{s i}}$ denote the national and provincial carbon emission density, respectively.

If the calculation result is that EDI is greater than 1, the provincial carbon emissions per capita is less than the national average, and the province will have a relatively high carbon emissions space in the future according to the principle of fairness; however, if the EDI is less than 1, the provincial carbon emissions per capita is higher than the national average and the provincial carbon emission has the characteristic of encroaching on other regional carbon emission benefits.

\section{3) Economic efficiency index (EEI)}

From the perspective of the economy, if the proportion of carbon emissions in one province is greater than the proportion of the GDP that that province generates, then the province exhibits a relatively low economic efficiency and it thus encroaches on the interests of other provinces; on the contrary, if the proportion of carbon emissions in one province is less than that of its GDP, then the province exhibits a higher economic efficiency. Thus, in this paper, the economic efficiency index (EEI) mainly uses the provincial GDP as a reference to be calculated; the EEI formula is as follows:

$\mathrm{EEI}=$ the rate of economic contribution/the ratio of carbon emissions.

$E E I=\frac{G_{i}}{G} / \frac{Y_{i}}{Y}$

in which $G_{i}$ and $G$ are the regional and national GDP, respectively, and $Y_{i}$ and $Y$ are the carbon emissions of the province and the whole of China, respectively. If the calculated result is greater than 1 , the provincial carbon emission is with high economic efficiency; on the contrary, if the calculated result is less than 1 , the province is of low economic efficiency.

\subsection{Construction of the evaluating matrix for China's carbon emissions}

As to the study of spatial difference in China's carbon emission, Lu Junyu etc. (2012) used Giny index to describe China's carbon emissions in 2010. Referring to their method, we constructed an evaluation matrix by using the ESIs and EEIs of each province according to the conditions in Table 1. Then we divided China's provinces into different groups with this evaluation.

\section{Results and analysis}

3.1. Analysis of the differences in spatial and temporal changes for China's carbon emissions based on the $3 E$ model

Using the default carbon content and the default $\mathrm{CO}_{2}$ emission factors of various fuels provided by IPCC2006, the authors
Table 1

Spatial difference evaluation matrix of China's carbon emissions.

\begin{tabular}{lll}
\hline $\begin{array}{l}\text { Evaluation } \\
\text { coefficient }\end{array}$ & EEI $>1$ & EEI $<1$ \\
\hline ESI $>1$ & $\begin{array}{l}\text { Group 1: Regions with both } \\
\text { high economic efficiency and } \\
\text { high ecological support for } \\
\text { carbon emissions. }\end{array}$ & $\begin{array}{l}\text { Group 2: Regions with low } \\
\text { economic efficiency but high } \\
\text { ecological support for carbon } \\
\text { emissions. }\end{array}$ \\
& $\begin{array}{l}\text { Group 3: Regions with high } \\
\text { economic efficiency but low } \\
\text { ESI }<1\end{array}$ & $\begin{array}{l}\text { Group 4: Regions with both } \\
\text { low economic efficiency and 1 } \\
\text { ow ecological support for } \\
\text { ecological support for carbon }\end{array}$ \\
& emissions. & \\
\hline
\end{tabular}

calculated the $\mathrm{CO}_{2}$ emissions of each province in 2000, 2005 and 2010 according to formulae (2), (3) and (4). At the same time, each province's total carbon sink capability in 2000, 2005 and 2010 were calculated by the forest and grass carbon exchange rate value multiplied by the corresponding land cover data, which were extracted from the time series of the remote sensing data. Then, the 3E model could be computed using the ESI, EDI and EEI based on the province's population, land area and GDP data from China's statistical yearbooks of 2000, 2005 and 2010. The specific results are as follows.

\subsubsection{ESI differences analysis}

The ESIs of different provinces in China were calculated with formula (6) and then with Arcmap10.0 we formed their spatial distribution in Fig. 3. Fig. 3a,b and c stand for their distribution in 2000, 2005 and 2010 respectively. We can see that in nationwide, Chinese provinces can be obviously divided into three groups according to ESIs. The first group with ESI $<0.5$ is mainly distributed in the eastern coastal with high carbon emissions, such as provinces of Beijing, Tianjin, Hebei, Shandong, Shanghai and Jiangsu. It indicates that these regions' carbon sinks contribute less than their carbon emissions and they have relatively low carbon ecological capacity needing other areas to share their emissions. Although Ningxia is inland, its ESIs are small. This may lies in that its lower forest coverage leads to lower carbon sequestration while it has more carbon emissions along with its economic development. The second group $(0.5<\mathrm{ESI}<0.5)$ is in balance between its carbon sink and carbon emission. It includes provinces with high emissions and high carbon sequestration like Zhejiang, Chongqing, Guangdong, Taiwan and Hubei, etc. and provinces with low emissions and low carbon sink like Xinjiang, Gansu, etc. These provinces are mainly distributed in the central and western regions of China with their carbon sink abilities of ecosystem offsetting their carbon emissions. The third group (ESI > 1) is mainly distributed in the Midwest high forest coverage rate of northeast three provinces (Heilongjiang, Jilin, and Liaoning), three provinces in the southwest (Yunnan, Guizhou and Sichuan), three provinces in the southeast (Fujian, Jiangxi and Hunan) and three western provinces (Qinghai, Tibet and Inner Mongolia). These provinces have large forest and grass coverage rate, while their economy maintains to a medium development with their carbon emissions not large. So their high ESIs indicate that these areas have high carbon ecological capacity and their redundant ecosystem carbon sinks are occupied by other provinces with high emissions.

From the comparison of Fig. 3a, b and c, we can see that there are 17 provinces whose ESIs are becoming smaller as their economic development increases, leading to increases in carbon emissions. These regions include the western provinces, such as Xinjiang, Qinghai and Xizang, and the southern provinces, such as Hainan, Guangxi, Fujian and Yunnan. The ESIs of 15 provinces are becoming higher and have both low carbon emissions and high carbon sink capability; these provinces are mainly distributed in the three 


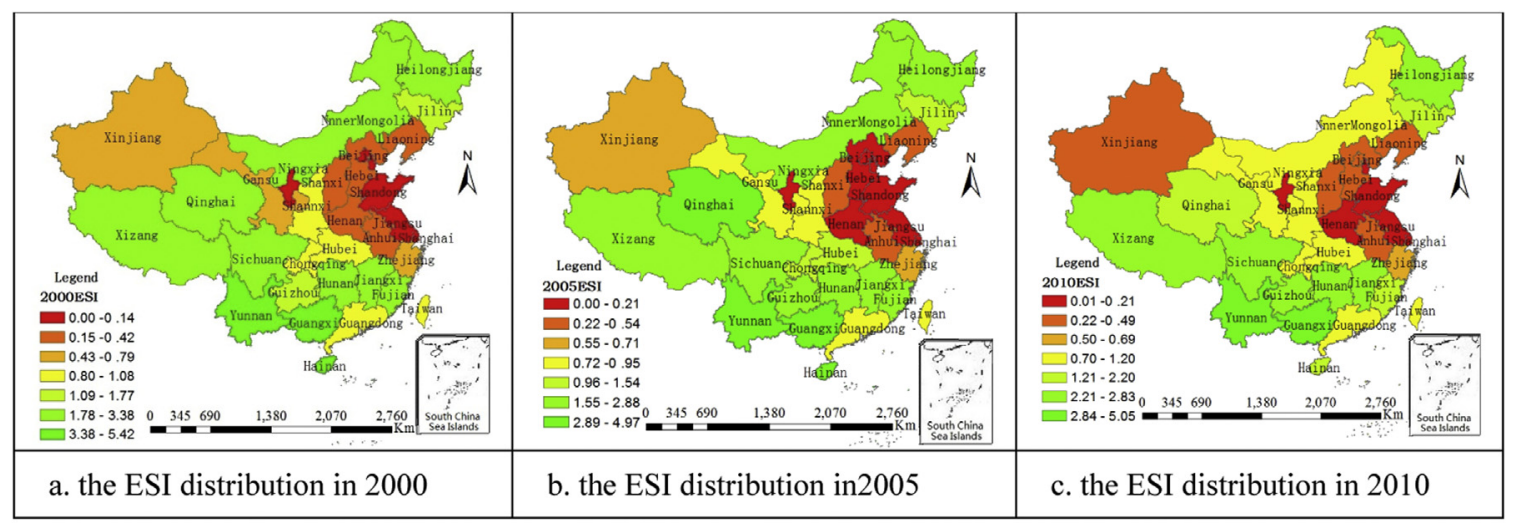

Fig. 3. ESI distribution of China's provinces in different years.

northeastern provinces (Heilongjiang, Jilin, and Liaoning), southwest provinces (Sichuan, Chongqing and Guizhou) and southeast provinces (Guangdong and Taiwan). There are significant spatial differences in China's carbon sources and sinks, according to the distribution of the ESIs. Additionally, the ESIs in the central and western frontier provinces are becoming smaller, and the ESIs in the east coastal area are becoming larger, which is very helpful for reducing the carbon ecological support differences and increasing the fairness of the regional carbon emissions. To reduce these differences between eastern and western China, the eastern coastal areas should reduce their carbon emissions and increase their carbon sink capability, and western China should accelerate their economic development.

\subsubsection{EDI differences analysis}

Based on formula (7), we calculated the EDIs in 2000, 2005 and 2010, and got their spatial distributions (seen in Fig. 4) with the help of ARCMAP 10.0 .

In Fig. 4, we can see that there are distinct differences in EDIs' spatial distribution in China. The first group with EDI lower than 0.6 is mainly distributed in north China and Yangtze river delta, including provinces of Beijing, Shanghai, Tianjin, Jiangsu, Liaoning, Shanxi, Shandong, Hebei, Henan, Zhejiang, Guangdong and Taiwan. The per capita and per area carbon emissions in these regions are much higher than the national average level, which indicated that they are using the carbon emissions space of other provinces from the perspective of fairness. The second group $(0.6<\mathrm{EDI}<1.2)$ is mainly distributed in south and the north of China, including provinces of Xinjiang, Inner Mongolia, Heilongjiang, Jilin, Ningxia, Anhui, Hubei and Guizhou. With medium economic development, carbon emissions in these areas are moderate and their per capita and per area carbon emissions are in a national average level. The third group (EDI $>1.2$ ) is mainly distributed in the southwest and the Qinghai-Tibet plateau area, including provinces of Tibet, Qinghai, Yunnan, Guangxi, Hainan, Sichuan, Hunan and Jiangxi. These regions have large land area while their population and carbon emissions are not too big, which leads to their per capita carbon emissions less than that of the national average, so they have relatively high carbon emission space.

In Fig. 4, the EDIs in the provinces of Guangdong, Fujian, Hebei, Shaanxi, Hubei, Zhejiang and Sichuan are observed to have decreased rapidly over 10 years because of their increasing per capita and per area carbon emissions resulting from economic development. In contrast, the EDI values in the Tianjin, Shanghai, Xinjiang, Hunan, Guizhou, Anhui and Shandong provinces increased significantly because they adopted measures to reduce emissions and increase carbon sinks as part of their economic development, which indicated that the economically developed eastern provinces were willing to adopt and to use emission reduction technologies widely in compliance with national policy and with financial support when their economies reached a certain size. The EDIs in the eastern coastal area are low; due not only to the spatial distribution but also to the time scale changes, which indicates that the carbon intensity and density in the eastern provinces are higher than the national average, as their current economic development encroaches on the carbon emissions space of other regions. In contrast, the EDIs in the Midwest regions are universally high and their carbon intensity and density is low; thus, they have a large carbon emission space. In the future, as China's emphasis on economic development moves to the west and the eastern coastal regions increase their carbon sink capabilities, the EDI difference between the east and west will gradually decrease.

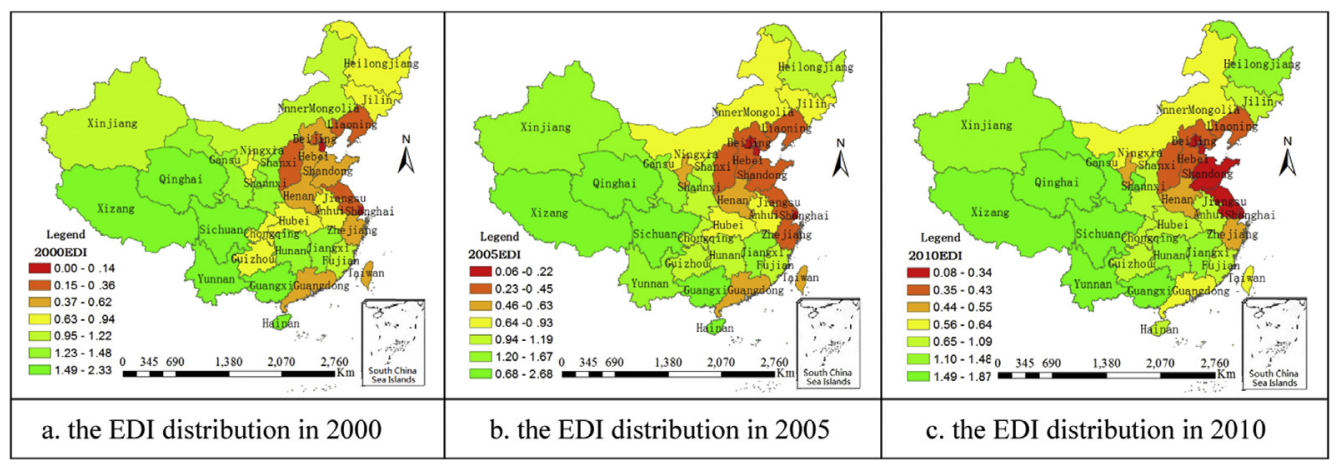

Fig. 4. EDI distribution of China's provinces in different years. 


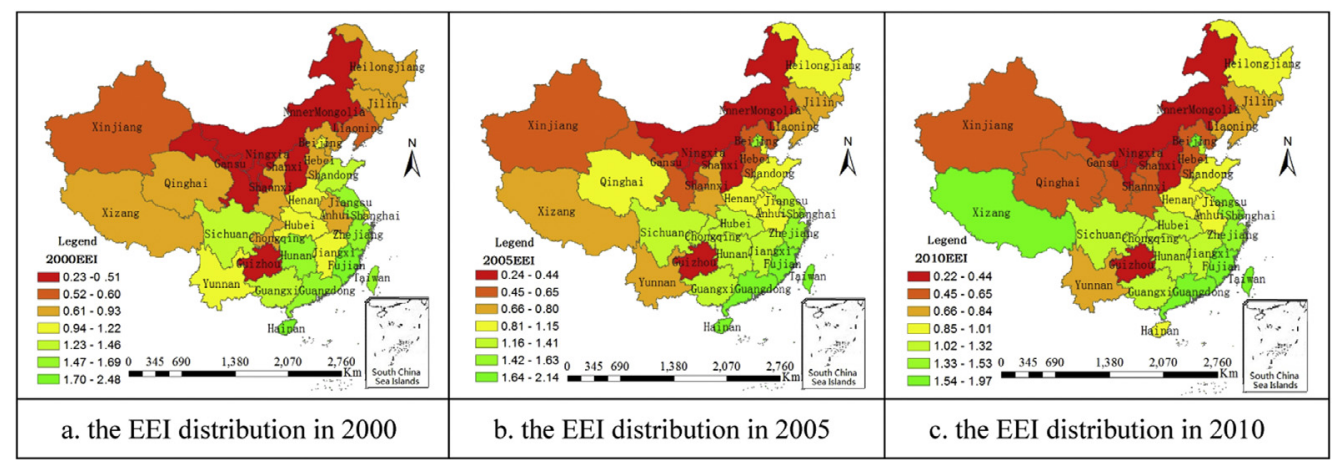

Fig. 5. EEI distribution of China's provinces in different years.

\subsubsection{EEI differences analysis}

According to the EEI formula, we calculated the EEIs of 2000, 2005, 2010 in China and formed their spatial distribution in Fig. 5.

As is shown in Fig. 5 that the high EEIs is mainly distributed in the southeast area including the eastern coastal provinces, which indicated that the economic contribution rate in this region is greater than its contribution rate of carbon emissions, and this region has higher economic efficiency. While the provinces in northwest China, with their slow economic development, poor infrastructure and unreasonable economic structure which mainly included low value-added industries and relying much on energy, their unit carbon efficiency is low. The lower EEIs show that the regional economic contribution rate is less than that of its carbon emissions, and their economic development has infringed the rights of other regions' carbon emissions.

Comparing Fig. 5a,b and c,we can see that the EEIs increased significantly, which meant the per unit GDP of the carbon emissions efficiency were improved significantly following China's economic development and industrial structure adjustments in the past 10 years, as has occurred in the provinces of Beijing, Shanghai, Tianjin, Heilongjiang, Jilin, Liaoning, Guangdong, Chongqing, Hubei, Anhui and others. In contrast, the EEIs in the Shanxi, Inner Mongolia, Ningxia and Guizhou provinces are less than 0.5 and they are the four lowest EEIs in China. Examining nearly 11 years of data, the EEIs in the provinces of Fujian, Shandong, Henan, Shanxi, Hunan, Hainan, Chongqing, Yunnan, Ningxia and others exhibit an obvious downward trend, i.e., their lower carbon emissions of per unit GDP indicate that these regions exhibit slow adjustment of industrial structures and lack sufficient technical content and that their enterprises primarily use energy resources and provide low-valueadded products. We can observe that the EEI represents the efficiency of China's carbon emissions from an economic perspective and indicates that the efficiency per unit GDP of carbon emissions differs significantly because of the difference in China's economic and industrial structures. As the industrial structure is adjusted and a low-carbon economy is developed, the efficiency of carbon emissions will be gradually improved in eastern China through the technical innovation of many enterprises and the introduction of new technologies.

\subsection{4. $Y_{3 E}$ differences analysis}

According to the results of the Delphi analysis, which determined the weights of the ESI, EDI, and EEI to be $40 \%, 20 \%$ and $40 \%$, respectively, the authors calculated the values of $Y_{3 E}$ in 2000, 2005 and 2010 by formula (5) and mapped their distribution, as shown in Fig. 6.

Fig. 6 indicates that half of the $Y_{3 E}$ values of China's provinces and autonomous regions are greater than 1 , which suggests that the carbon emissions in these regions for nearly a decade are benign overall in terms of ecosystem circulation and fairness and economic efficiency in carbon emissions. The $Y_{3 E}$ values are increasing in the Jilin, Chongqing, Guizhou and Heilongjiang provinces, while they are decreasing in the Hainan, Yunnan, Guangxi and Qinghai provinces. The $Y_{3 E}$ values in the Beijing, Zhejiang and Gansu provinces in 2010 are close to 1, especially in Beijing, where they increased from 0.51 in 2000 to 0.96 in 2010, which indicates that they will soon be over 1.0 according to this trend. From Fig. 6, we conclude that most of China's coastal provinces are moving in lower-carbon, ecologically favorable and high-efficiency directions, as they are influenced by China's low-carbon economic policy and by all means of technical innovation, system innovation, industrial transformation and new energy development.

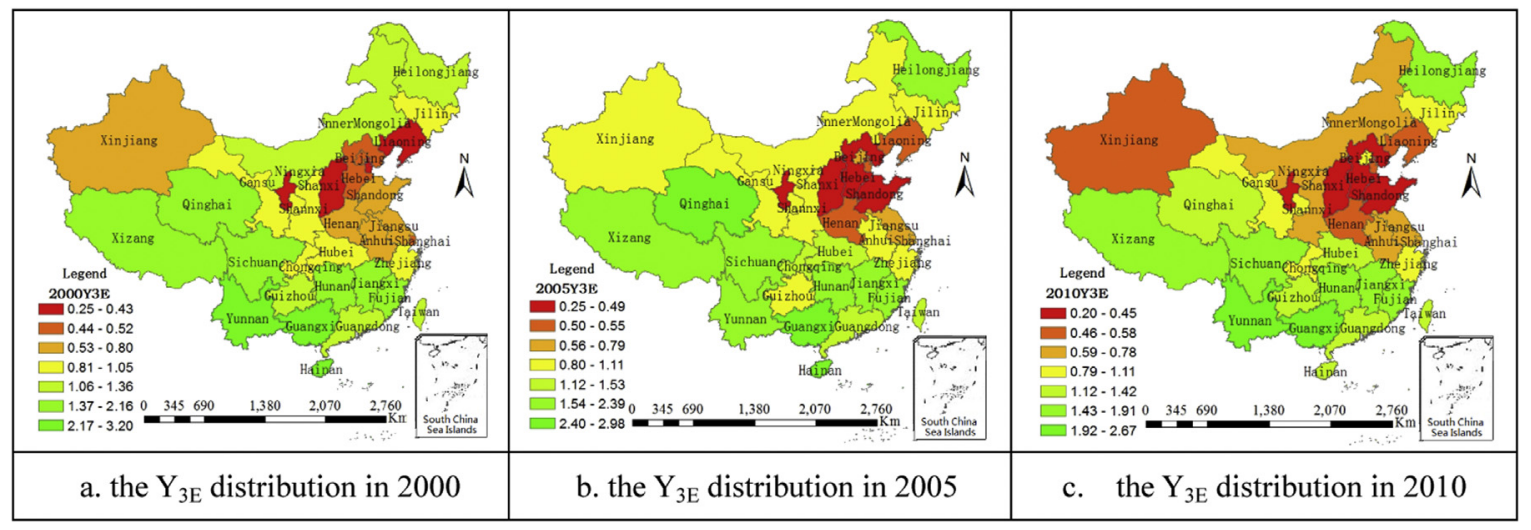

Fig. 6. $\mathrm{Y}_{3 \mathrm{E}}$ distribution of China's provinces in various years. 


\subsection{Spatial difference analysis based on an evaluation matrix of China's carbon emissions}

According to Table 1, China's carbon emissions spatial difference matrix in 2010 is shown in Table 2 with the use of ESIs and EEIs.

From Table 2, we can observe that the regions with relatively high economic efficiency and ecological capacity for carbon emissions are mainly distributed in the provinces in southern China, which has a large forest area, a high carbon exchange rate and rapid economic development, as in group 1 . The regions with low economic efficiency but high ecological support for carbon emissions are mainly distributed in the northeast and the southwest forestcovered areas of China with moderate economic development, as in group 2. The regions with high economic efficiency but low ecological support for carbon emissions are mainly distributed in the eastern China coastal regions that exhibit high economic development and have low forest or grass coverage, as in group 3. The regions with both low economic efficiency and low ecological support for carbon emissions are mainly distributed in the midwest and the coastal areas of China, where the carbon sinks of the ecological environment are not too large but the economy is relatively developed as in group 4 .

By comparing the matrices of the changes between 2000, 2005 and 2010, we find that China's carbon emissions decreased over the nearly decade-long period of rapid economic development in the face of climate change and the Kyoto protocol, which delineated each country's emissions reduction tasks. China has increased energy saving and passed emission reduction acts and has developed related policies to guide and promote these policies; in particular, the eastern coastal provinces have reduced their carbon emissions through technology introduction and enterprise structure adjustment. Although their ESIs and EEIs in China vary based on economy and afforestation, the four groups are basically stable, which indicates that China's national reform policy and afforestation effects are basically the same across the provinces.

\section{Discussion}

When we use the traditional method to describe China's provincial differences of carbon emissions, we can only see their differences in absolute quantity like the carbon emissions in provinces of Shandong, Hebei, Jiangsu, Shanxi, Inner Mongolia autonomous region, Liaoning, Henan, Zhejiang, Guangdong, Hubei, Sichuan and Heilongjiang are large, while carbon emissions in provinces of Qinghai and Hainan are small in 2010. As we turn to the evaluation matrix of China's carbon emissions we can see provincial differences of carbon emissions under their own economy and ecology. Although absolute quantity of carbon emissions in Hubei and Sichuan provinces is large, their economy develops fast and their ecological capacity is large too. So these two provinces are in the first

Table 2

Spatial difference evaluation matrix of China's carbon emissions in 2010.

\begin{tabular}{lll}
\hline $\begin{array}{l}\text { Evaluation } \\
\text { coefficient }\end{array}$ & EEI $>1$ & EEI $<1$ \\
\hline ESI $>1$ & $\begin{array}{l}\text { Group 1: Chongqing, Hubei, } \\
\text { Sichuan, Fujian, Hunan, Jiangxi, } \\
\text { Hainan, Guangxi (in which } \\
\text { added Chongqing than 2000) }\end{array}$ & $\begin{array}{l}\text { Group 2: Jilin, Guizhou, } \\
\text { Heilongjiang, Inner Mongolia, } \\
\text { Tibet, Qinghai, Yunnan (in } \\
\text { which added Shaanxi and } \\
\text { Yunnan than 2000) }\end{array}$ \\
& $\begin{array}{l}\text { Group 3: Tianjin, Shanghai, } \\
\text { Group 4: Ningxia, Shandong, }\end{array}$ & $\begin{array}{l}\text { Hebei, Henan, Shanxi, Liaoning, } \\
\text { ESI }<1\end{array}$ \\
& $\begin{array}{l}\text { Guangsu, Beijing, Zhejiang, } \\
\text { added Tianjin than 2000) } \\
\text { (in which added Shandong, }\end{array}$ & $\begin{array}{l}\text { Henan, Shanxi than 2000 and } \\
\text { removed Anhui than 2005) }\end{array}$ \\
& &
\end{tabular}

group of the evaluation matrix. While Shandong, Hebei and Shanxi provinces are still in the fourth group with both low economic efficiency and low ecological support for carbon emissions. From this point we can see that evaluation matrix of China's carbon emissions can help us analyze the regional differences more in detail. When referring to the fairness of the carbon emissions, per capital carbon emissions is often used. In our newly built 3E model, we use not only per capital carbon emission but also the carbon emission intensity to enhance the regional fairness. Thus with the $\mathrm{Y}_{3 \mathrm{E}}$ values we can see the pattern differences and the equity of national carbon emissions more clearly. The values of $\mathrm{Y}_{3 \mathrm{E}-2010}$ in Guangdong, Hubei, Sichuan and Heilongjiang provinces are all greater than 1 , which indicates that these regions are in the efficient development under their ecological carrying no matter from the point of ecology and fairness .So in the future in the decision-making of allocation for carbon emissions rights, these regions can be moderately relaxed. While in provinces of Shandong, Jiangsu, Shanxi and Hebei whose Y YE-2010 values are small, it is important for them to take great efforts to develop their low carbon economy.

Being a developing country, China will inevitably consume a large amount of energy in the process of rapid economic and social development, which will result in a large amount of carbon emissions. The key to addressing these emissions is ensuring that China has enough space to "contain" them. Space to contain carbon emissions is gradually becoming scarcer compared to labor, capital, land and other natural resources because of its limited nature and irreplaceability. As a result, over the past 20 years, the Chinese government has launched six major afforestation projects, which include the following: the natural forest protection project (1998-2008), the returning farmland to forest project (since 1997), the key protection forest system construction project of the "three norths" and the middle and lower reaches of the Yangtze river (the three periods are 1978-1985, 1986-1995, 1996-2000), the sandstorm source management project in Beijing and Tianjin (2003-2007), the wildlife protection and nature reserve construction project (2001-2010) and the fast-growing and highyielding commercial forest base construction project in the key areas (beginning in 2002). Due to the influence of these six major afforestation projects, China's forest coverage fraction increased from $25.99 \%$ in 2000 to $27.24 \%$ in 2010 . At the same time, the returning farmland to forest and grass in China and its afforestation policy have also contributed to increasing China's ecosystem carbon sink capacity.

Climate change and the "Kyoto protocol" have influenced increasing numbers of people internationally to believe that implementing a low-carbon economy is required to realize sustainable development in the future. The Copenhagen conference has opened door to low-carbon economy development. Many countries have announced their carbon emissions targets, and the Chinese government also committed to a $40 \%-45 \%$ reduction per unit GDP of the 2005 by 2020 carbon emissions. Additionally, the state environmental protection agency proposed their targets and measures regarding the development of a green economy, a lowcarbon economy, and a circular economy in response to climate change and the pressures of international responsibility. In addition to technological innovation, the use of new energy, new technology and the improvement of carbon productivity and LULUCF (land use, land use change and forestry) are good ways to increase the number of carbon sinks, expand the carbon emission space and increase the potential for China's economic development.

\section{Conclusion}

This article described the calculation of corresponding periods of ecosystem carbon sinks using land cover data in 2000, 2005 and 
2010 extracted from time-series remote sensing data by supervised classification, followed by calculation of the ESI, EDI, EEI using a 3E model combined with statistical data to analyze spatial pattern differences and the changes in China's carbon emissions over ten years. The conclusions are that the $\mathrm{Y}_{3 \mathrm{E}}$ values of half of China's provinces and autonomous regions are greater than 1, which indicates that the carbon emissions in these areas over nearly a decade are benign overall in terms of ecosystem circulation and that there is fairness and economic efficiency of carbon emissions. That the $\mathrm{Y}_{3 \mathrm{E}}$ values in Beijing, Zhejiang and Gansu in 2010 are close to 1 indicates that most of China's coastal provinces are moving in a low-carbon, ecologically favorable and high-efficiency direction, as they are influenced by China's low carbon economic policy.

The newly-built 3E model by using the framework of ecologyequity-efficiency, can not only provide a new way to study the regional differences of carbon emissions with very strong pertinence and comparability in a year, but also can describe provincial reasonable carbon emission trends, which could provide certain references to the reasonable distribution of the carbon emission credits, for China's regional economic development and the implementation of its low-carbon economic policy and provide guidance for China's spatial planning of LULUCF to increase the carbon sink capacity.

However in view of the ecological system, the response time of the carbon emissions cycle is commonly 20 years or so (Lai.2011). If conditions permitting, we would extend the research time scale in the future to make 3E model an aid to describe the pattern changes of China's province carbon emissions.

\section{Acknowledgments}

This work was supported from the Key Research Program of the Chinese Academy of Sciences(KZZD-EW-14),National Natural Science Foundation of China (41171334), Talent Fund of Yantai Institute of Coastal Zone Research, Ecological Innovation \& Breeding Project (Y254021031,Y355031061), USDA NIFA Project (201034263-21075) .

\section{References}

Cai, Z.C., Kang, G.D., Tsuruta, H., 2005. Estimate of $\mathrm{CH}_{4}$ growing season in China. Pedosphere 4 (2), 15-25.

Chen, H., Zhu, D.J., Zou, L., 2012. Research on carbon dioxide emissions space in main countries around the world - based on ecology, fair and efficiency model. J. Northeast. Univ. Soc. Sci. Ed. 3 (14), 120-124.

Cox, P.M., Betts, R.A., Jones, C.D., Spall, S.A., Totterdell, I.J., 2002. Modelling vegetation and the carbon cycle as interactive elements of the climate system. Int. Geophys. Ser. 34 (3), 345-356.

De Carvalho, O.A., Guimaraes, R.F., Gomes, R.A.T., de Carvalho, A.P.F., da Silva, N.C., 2006. Normalization of multi-temporal images using a new change detection method based on the spectral classifier. In: IGARSS'06, 4, pp. 771-774.

Ding, Z.L., Duan, X.N., Ge, Q.S., Zhang, Z.Q., 2009. Controlling of atmospheric $\mathrm{CO}_{2}$ concentration in 2050: national emissions calculation. China Sci. D. 8.

Duro, J.A., 2013. International mobility in carbon dioxide emissions. Energy Policy $55,208-216$.

Energy Research Institute, the team of China's sustainable development of energy and carbon emissions, 2003. The scenario study on China's sustainable development of energy and carbon emissions. J. Res. Explor. 25 (6), 4-10.

Fang, J.Y., Guo, Z.D., Piao, S.L., 2007. The estimation of Chinese terrestrial vegetation carbon sequestration in 1981-2000. Sci. China 5 (6), 804-812.

He, Y., 2006. Research on Carbon Cycle in China's Climate and Terrestrial Ecosystem. meteorological press, Beijing, p. 25.

Huang, B.J., Yang, H.Z., 2011. Interpretation on China's promise of carbon emission reduction and its carbon trading development research. J. Resour. Environ. Yangtze River S2, 11-13.
International Energy Agency, 2010. World Energy Outlook 2010. Organization for Economic Cooperation and Development, Paris.

IPCC, 2006. 2006 IPCC Guidelines for National Greenhouse Gas Inventories. Prepared by the National Greenhouse Gas Inventories Program Eggleston H S Buendia L., Miwa K., et al. IGES, Japan.

IPCC, 2007a. Summary for Policymakers of the Synthesis Report of the IPCC Fourth Assessment Report. Cambridge University Press, Cam bridge, U K.

IPCC, 2007b. Contribution of Working Group III to the Fourth Assessment Report of the Intergovernmental Panel on Climate Change. Cambridge University Press, Cambridge.

IPCC, 2007c. Summary for Policymakers of Climate Change 2007: the Physica Science Basis. Cam 2 bridge University Press, Cambridge.

IPCC, 2008. Climate Change 2007: a Comprehensive Report. The Intergovernmental Panel on Climate Change (IPCC). Press, Beijing.

Lai, li, 2011. Research on Carbon Emission Effects of China's Land Use. Nanjing University Press.

Leemans, R., Eickhout, B., Strengers, B., 2002. The consequences of uncertainties in land use, climate and vegetation responses on the terrestrial carbon. Sci. China Series Life 45, 230-245.

Li, G.Z., Li, Z.Z., 2010. Research on the regional differences and their influence factors of China's carbon dioxide emissions. China Popul. Resour. Environ. 20 (5), 22-27.

Li, H.M., Qi, Y., 2011. Scenario comparisons of China's carbon emissions in 2050. Res. Prog. Clim. Change 4, 271-280.

Li, Z.M., Sun, Y.H., 2011. The comparative study of provincial carbon emissions driver based on IPAT formula. Sci. Technol. Prog. Countermeas. 28 (2), 39-42.

Liao, H., Wei, Y.M., 2011. The forecast and prospect of "twelfth five-year" in China's energy and carbon emission. Proc. Chin. Acad. Sci., 02.

Lu, J.Y., Huang, X.J., Dai, J., 2012. The equity analysis on China's provincial carbon emissions for their energy consumption in temporal and spatial scale. J. Nat. Resour. 27 (12), 2006-2017.

National bureau of statistics (NBS), 2001-2012a. China energy Statistical Yearbook 2000-2011. China Statistical Publishing House.

National bureau of statistics (NBS), 2001-2012b. China Cement Statistical Yearbook 2000-2011. China Statistical Publishing House.

National Bureau of Statistics (NBS), 2001-2012c. China Statistical Yearbook 2000-2011. China Statistical Publishing House.

National Bureau of Statistics (NBS), Gong Jiao Si, 2010. Energy statistics Knowledge Handbook. National Bureau of Statistics.

Peng, G.X., Deng, L., Cui, W.H., Tao, M., Shen, W., 2009. Remote sensing monitoring of tobacco field based on phenological characteristics and time series image-a case study of Chengjiang County, Yunnan province, China. Chin. Geogr. Sci. 19 (2), 186-193.

Powlson, D.S., Whitmore, A.P., Goulding, K.W.T., 2011. Soil carbon sequestration to mitigate climate change: a critical rexamination to identify the true and the false. Eur. J. Soil. Sci. 62 (1), 123-134.

Qin, D.H., Luo, Y., Chen, Z.L., 2007. The progress of climate changing science, the analysis on the fourth comprehensive assessment report of IPCC. J. Clim. Change Res. Prog. 3 (6), 311-314.

Shu, Y.Q., 2012. The time and space characteristics of China's carbon emissions for energy consumption. Acta Ecol. Sin. 4 (12), 4950-4960.

Tang, H., Du, P.J., Fang, T., Shi, P.F., 2005. The analysis of error sources for SAM and its improvement algorithms. Spectrosc. Spectr. Anal. 25 (8), 1180-1183.

Wang, Y.S., Du, M.Y., Li, Y.N., 2008. Comparison of eddy covariance and static chamber gas chromatogram methods in measuring ecosystem respiration. Chin. App1. Eco1. 19 (2), 290-298.

Wang, Q.X., Gao, Z.Q., Ning, J.C., 2014. Model building discussions on the differences among provincial carbon emissions in China based on fairness-An example of carbon emissions in China in 2010. Resour. Sci. 05, 998-1004.

William, L.S., Maik, N., 2005. Assessment of ASTER land cover and MODIS NDVI data at multiple scales for ecological characterization of an arid urban center. Remote Sens. Environ. 99 (1), 31-43.

Xiong, Y.L., Zhang, Z.Q., Qu, J.S., 2012. The characteristics research on China's provincial $\mathrm{CO}_{2}$ emission in 2005-2009. J. Nat. Resour. 27 (12), 1766-1777.

Xu, G.Q. Liu, Z.Y. Jiang, Z.H., 2006. China's carbon emissions factor decomposition model and its empirical analysis: 1995-2004. China Popul. Resour. Environ. 6, $158-161$.

Zeng, X.G., Pang, H.S., 2010. The study on the situation, trend and its reduction countermeasures for China's $\mathrm{CO}_{2}$ emissions in each province. Suppl. J. China Soft Sci. Top. 6, 65-71.

Zha, D.L., Zhou, D.Q., 2007. The differences between regional energy efficiency and carbon emissions - based on the Kaya factorization. J. Syst. Eng. 2 (511), 65-71.

Zhang, X.M., Li, S.F., Huang, X.J., Li, Y., 2010. Analysis on carbon emissions effect of Jiangsu province from 1996 to 2007 and its space-time pattern. J. Resour. Sci. 32 (4), 768-775.

Zou, X.P., Song, D.J., 2013. The analysis on the regional differences and their driving factor decomposition for China's carbon emissions. Ecol. Econ. 1, 52-55. 